\section{Racemose cysticercosis: A summary of 5 reported Thai cases}

Sir,

Cysticercosis is an important trematode infestation caused by Taenia solium larva. At present, cysticercosis is considered an important public health problem, affecting people in several countries around the world. ${ }^{[1,2]}$ This parasitic infestation mainly manifests as tissue infiltration. The parasite can affect any organs. In superficial tissue infiltration, the cysticercosis can be accidentally detected as a soft tissue mass. ${ }^{[1]}$ In case of internal organ involvement, the infestation will have a more serious clinical presentation. ${ }^{[1]}$ The neurocysticercosis is the specific cysticercosis of the neurological system. In central nervous system, there are two main forms of neurocysticercosis. ${ }^{[3]}$ One is "isolated cyst" (cysticercus cellulosae) and the other is "racemose cyst (cysticercus racemosus)."[1] The racemose cysticercosis is a specific extremely rare form of neurocysticercosis that the parasitic cysts are usually detected at the basal subarachnoid region. ${ }^{[4]}$ The appearance of racemose cysticercosis looks like "a collection of transient membranes forming a cluster like a bunch of grapes." ${ }^{[3]}$ Less than 80 reports are documented in PubMed. In this short article, the authors report a summary on previous publications on Thai patients with racemose cysticercosis. According to the literature search (PubMed and ThaiIndexMedicus), there are at least 5 Thai cases ( 3 males and 2 females, aged between 25 and 52 years old) with racemose cysticercosis. ${ }^{[5-8]}$

Focusing on the clinical presentations, there are meningitis (5 cases), increased intracranial pressure (4 cases), hydrocephalus (1 case), seizure (1 case), hearing loss (1 case) and Pakinsonism (1 case). "Numerous rim-enhancing cystic lesions" is the main finding from brain imaging. Of these 5 cases, 4 cases were diagnosed by histological examination of surgical removal specimen and the left 1 case was diagnosed by autopsy study. In the death case, the co-infection by sparganosis is detected. All 4 cases that get confirmed diagnosis by histological examination of surgical removal specimen get postoperative albendazole treatment. However, 1 of these 4 cases died from status epilepticus, and septic shock (overall death $=2$ from 5 cases) whereas the other 3 cases got complete recovery without sequelae.

Based on this summary, there are many new interesting considerations. First, racemose cysticercosis seems to be a serious, deadly infestation that can result in a high fatality. The role of imaging diagnosis is usually limited and might be difficult to differentiate from other common tropical meningitis such as tuberculosis meningitis. Second, if the surgical removal is successfully done, the complete recovery can be derived. Third, the concomitant disease by other neurological problem such as sparganosis can be observed.

Somsri Wiwanitkit, Viroj Wiwanitkit ${ }^{1}$

Wiwanitkit House, Bangkhae, Bangkok, ${ }^{1}$ Hainan Medical University, Hainan, China

Address for correspondence:
Dr. Somsri Wiwanitkit,
Wiwanitkit House, Bang Khae,
Bangkok, Thailand.
E-mail: somsriwiwan@hotmail.com

\section{References}

1. Prasad KN, Prasad A, Verma A, Singh AK. Human cysticercosis and Indian scenario: A review. J Biosci 2008;33:571-82.

2. Wu W, Qian X, Huang Y, Hong Q. A review of the control of clonorchiasis sinensis and Taenia solium taeniasis/cysticercosis in China. Parasitol Res 2012;111:1879-84.

3. Agapejev S. Neurocysticercosis: The enigmatic disease. Cent Nerv Syst Agents Med Chem 2011;11:261-84.

4. Das RR, Tekulve KJ, Agarwal A, Tormoehlen LM. Racemose neurocysticercosis. Semin Neurol 2012;32:550-5.

5. Jarupant W, Sithinamsuwan P, Udommongkol C, Reuarrom K, Nidhinandana S, Suwantamee J. Spinal cord compression and bilateral sensory neural hearing loss: An unusual manifestation of neurocysticercosis. J Med Assoc Thai 2004;87:1244-9.

6. Tansanee P. Neurocysticercosis presenting with Parkinsonism: A case report. Bull Dep Med Serv 1992;17:565-9.

7. Pongprasert S. Sparganum mansoni combined with cysticercus cellulosae infected in pontomedullary junction in the same patient, presented with two clinical states: A case report. Bull Lampang Hosp 1985;6:225-50.

8. Chayapum P, Tungsinmunkong K, Shuangshoti S. Proliferating acephalic cestode larva of central nervous system. Chula Med J 1993;37:743-50.

\begin{tabular}{|l|l|}
\hline \multicolumn{2}{|c|}{ Access this article online } \\
\hline Quick Response Code: & Website: \\
\hline & www.ruralneuropractice.com \\
\cline { 2 - 3 } & \\
\hline
\end{tabular}

